\title{
Administração pública do setor elétrico: indicadores de sustentabilidade no ambiente residencial do estado do Pará (2001-10)
}

\author{
Fabricio Quadros Borges \\ Universidade da Amazônia
}

\begin{abstract}
Este artigo tem como objetivo apresentar uma proposta de indicadores de sustentabilidade de energia elétrica para a gestão pública junto ao setor residencial paraense que poderá servir de modelo para a gestão pública do setor elétrico também em outros estados brasileiros. A metodologia desta investigação baseou-se no suporte teórico do modelo PER, que envolve a relação pressão-estado-resposta. Os resultados demonstraram que o aspecto econômico é o que melhor reflete o insumo elétrico nos domicílios paraenses. O aumento da renda média, reflexo da disponibilidade de eletricidade e do aumento do consumo desse insumo, teve papel importante na economia paraense. Já o aspecto socioambiental apresentou indicadores médios com tendência decrescente.
\end{abstract}

Palavras-chave: sustentabilidade; indicadores; eletricidade; qualidade de vida.

Public administration's energy sector: sustainability indicators residential environment in the state of Pará (2001-10)

This article aims to present a proposal for indicators of sustainability of electricity for public management with the residential sector in Pará that could serve as a model for the governance of the electricity sector in other states. The methodology of this study was based on the theoretical model support PER, which involves the relationship pressure-state response. The results showed that the economic aspect is the one that best reflects the input power in the home in Para. The increase in average income, reflecting the availability of electricity and the increased consumption of this resource, played an important role in the economy Para. But the social and environmental aspect presented with a decreasing average indicators.

KEY words: sustainability; indicators; electricity; quality of life.

Artigo recebido em 16 jun. 2011 e aceito em 15 set. 2011.

RAP - Rio de Janeiro 46(3):737-51, maio/jun. 2012 


\section{Introdução}

O ambiente da administração pública do setor elétrico é desenvolvido através de políticas públicas que geralmente pretendem demonstrar que os investimentos objetivam o crescimento econômico e a melhoria das condições de vida da população. Para a compreensão conceitual desse ambiente apresentam-se duas categorias: a energia elétrica e o setor elétrico.

A energia elétrica compreende o produto de um processo adequado de uso de propriedades físico-químicas e eletromagnéticas da matéria para propiciar o funcionamento de equipamentos fornecedores de usos finais pela sociedade (Reis et al., 2005). Assim, ainda como ressaltam os autores, a energia elétrica constitui-se como uma energia secundária que pode ser adquirida através de fontes energéticas primárias transformadas a partir de conversores. Conforme Camargo e colaboradores (2004), as conversões de energia primária em elétrica mais utilizadas atualmente são de: energia térmica, que é aquela encontrada nos combustíveis fósseis e na biomassa através das usinas termelétricas; energia atômica de minerais radioativos a partir de usinas nucleares; e potencial hídrico através das usinas hidrelétricas.

O setor elétrico, por seu turno, constitui-se em uma organização social formada de relações sistêmicas que envolvem o processo de transformação da energia primária até a utilização final por tipo de consumidor. Essas relações são estabelecidas entre os componentes do setor elétrico, tais como: geração, transmissão e distribuição. De acordo com Reis e colaboradores (2005), a geração de energia elétrica compreende todo o processo de transformação de uma fonte primária de energia em eletricidade e representa uma parte bastante significativa dos impactos ambientais, socioeconômicos e culturais dos sistemas de energia elétrica. A eletricidade produzida nas centrais de geração percorre normalmente um longo caminho até seu local de uso. Esse percurso envolve os sistemas de transmissão, que interligam a geração aos centros de carga (nos casos onde a distribuição não se conecta diretamente à transmissão utilizam-se os sistemas de subtransmissão). A distribuição, por fim, compreende a rede que interliga a transmissão (ou a subtransmissão) aos pontos de consumo final.

O processo de expansão econômica de um país vincula-se a um aumento na oferta de eletricidade gerada por investimentos aplicados no setor energético e, por conseguinte, aumento do consumo. Analisando a história da relação entre energia e desenvolvimento, Reis e colaboradores (2005) mostram que políticas centralizadoras pautadas exclusivamente na oferta de energia são inadequadas às demandas básicas, causam prejuízos ao meio ambiente e proporcionam o crescimento autônomo de alguns setores em detrimento de outros, ocasionando disparidades sociais dentro de uma mesma região.

O potencial hidrelétrico do Brasil está entre os maiores do mundo, o que permitiu ao país direcionar-se à implantação de grandes projetos de geração de energia elétrica através do aproveitamento de vales fluviais inteiros. Entretanto, todo esse potencial a serviço do país apresenta dimensões econômicas, sociais e ambientais que interagem a partir de um panorama político.

Na região amazônica constata-se que quase a metade da eletricidade gerada se dá através do maior empreendimento hidrelétrico inteiramente nacional, a UHE de Tucuruí, que, 
por seu turno, está voltada para as chamadas indústrias energo-intensivas. A manutenção e a ampliação de processos produtivos que consomem muita energia geram poucos empregos e agregam baixos valores, demonstram que a dinâmica do processo de expansão econômica da Amazônia e todo seu discurso de desenvolvimento através da hidroeletricidade estão comprometidos mais com uma visão imediata de geração de PIB em curto prazo para o país do que com a melhoria da qualidade de vida da população amazônica. As dimensões social e ambiental também despertam preocupações na região. A social preocupa na medida em que as condições de acesso à energia elétrica vinculam-se às possibilidades de satisfação de demandas sociais básicas da população, que, quando não atendidas, tendem a favorecer um processo de exclusão. A ambiental pode ser objeto de impactos negativos na medida em que implica significativas alterações nos ecossistemas. A base de geração de energia elétrica pautada em empreendimentos hidrelétricos de grande porte e a transmissão desta energia, através dos linhões que desmatam milhares de quilômetros na floresta, caracterizam alguns destes impactos negativos.

Outro ponto que merece destaque é a relação entre quantidade de eletricidade utilizada e a quantidade efetivamente embutida no produto final desejado. De acordo com Smil (1993), a eletricidade é usada em diversos setores como o agropecuário, industrial, comercial e residencial. Em cada um deles a energia é transformada de acordo com os propósitos destas atividades, processo chamado de metabolismo energético-material, que no caso das sociedades industrializadas apresenta um intensivo consumo de matéria e energia. Neste sentido, o fluxo energético-material deve ser regulamentado através dos setores sociais e econômicos de modo que os recursos energéticos e materiais (renováveis e não renováveis) não sejam usados de forma predatória e possam garantir a sustentabilidade do metabolismo em longo prazo.

Diante desse cenário, os indicadores buscam avaliar as condições de desenvolvimento, atribuindo ordens de grandeza ao estado de sustentabilidade de um determinado setor de atividade econômica de forma a orientar o processo decisório no setor elétrico.

A sustentabilidade, por seu turno, é cercada de contradições. Conforme Kitamura (1994), a sustentabilidade vincula-se a uma ética que incorpora tanto os valores ecológicos quanto espirituais. O problema reside no fato de que os interesses econômicos não são submissos às noções de ética. Seu conceito supõe ainda uma nova ordem internacional, que tem como produto uma ampla redistribuição do poder (Kitamura, 1994). A ideia dessa nova ordem de desenvolvimento, entretanto, ignora as correlações de forças que são atuantes no mercado mundial e os interesses das nações industrializadas em manter a posição de vantagem no panorama internacional (Redclift, 1987; Spangenberg, 2000). O fato de os interesses econômicos não se subjugarem aos princípios éticos que acolhem valores ecológicos e espirituais compromete a essência da ideia terminológica do que seria o desenvolvimento sustentável. Os interesses das nações industrializadas, na manutenção da condição de vantagem econômica no cenário mundial, representam, na prática, a impossibilidade de implantação deste referencial normativo, pelo menos, a partir de suas bases conceituais. O contexto de implantação do desenvolvimento sustentável é caracterizado, inclusive, implicitamente, por padrões de uma 
economia de mercado, o que leva à conclusão de que a ideia deste tipo de desenvolvimento está profundamente vinculada a ideia de crescimento econômico.

A discussão sobre a relação entre desenvolvimento sustentável e energia vem sendo promovida por vários organismos internacionais que direcionam seus esforços na definição e na quantificação da sustentabilidade. Trata-se de indicadores de desenvolvimento, particularmente vinculados à questão da energia, que possuam a capacidade de demonstrar a condição de um país ou região no que se refere à sustentabilidade energética (Camargo et al., 2004). Em contexto regional, essa discussão destaca dois aspectos: a importância em desenvolver instrumentos científicos capazes de medir a relação entre o potencial hidrelétrico no estado do Pará e o aproveitamento do mesmo para um desenvolvimento socioeconômico da população a partir de ações públicas; e a possibilidade de pensar o desenvolvimento do estado do Pará vinculando o desenvolvimento do setor energético à melhoria da qualidade de vida da população paraense.

Todo esse contexto deve considerar o ambiente setorial de atividade na medida em que o insumo elétrico reflete o desenvolvimento de modo diferenciado em cada setor. O setor residencial, formado por consumidores domiciliares, representa um ambiente fundamental para que se avalie a realidade do desenvolvimento da população através da satisfação de suas necessidades energéticas básicas. Entretanto, os administradores do setor público necessitam de um conjunto de informações gerenciais para cumprir com eficiência, eficácia e efetividade as políticas públicas (Machado e Holanda, 2010). Desse modo, surge a necessidade de uma proposta de indicadores capaz de auxiliar a tomada de decisão no setor elétrico.

Diante do exposto, esta investigação questiona: como construir uma proposta de indicadores capaz de mensurar a sustentabilidade dos resultados dos investimentos em energia elétrica dentro das residências dos paraenses?

\section{Metodologia}

O processo de construção de indicadores para avaliação da sustentabilidade compreende um trabalho interdisciplinar em virtude de não haver um esquema padronizado de cálculo e interpretação. No enfrentamento desse desafio, a metodologia desta investigação compõe-se de três partes: objeto de estudo, procedimentos técnicos de investigação e descrição das variáveis.

\subsection{Objeto de estudo da investigação}

O objeto de estudo desta investigação é o estado do Pará. Detentor de uma área territorial de 1.247.689,515 km², o Pará está localizado na região Norte do país e possui uma população estimada de 7.431.020 habitantes (IBGE, 2009), o que registra ao estado uma densidade 
populacional por $\mathrm{km}^{2}$ de 5,95 habitantes. A base produtiva paraense encontra-se alicerçada na agroindústria e na produção mineral. O Produto Interno Bruto (PIB) do estado paraense, em 2007, foi de R \$ 49,507 bilhões, o que representou um crescimento de 11,5\% em relação ao ano anterior (Sepof, 2009). O Pará, dotado do maior potencial hídrico nacional e de característica exportadora de eletricidade, possui seu serviço público de distribuição de energia elétrica sob concessão das Centrais Elétricas do Pará (Celpa), enquanto o mercado de geração é de domínio das Centrais Elétricas do Norte (Eletronorte).

O setor residencial do estado do Pará será o ambiente de análise mais específico. Composto pelos consumidores domiciliares conectados regularmente às redes de distribuição de energia elétrica, o setor residencial compreende ambiente fundamental para que se examine a realidade da satisfação das necessidades energéticas básicas. Na medida em que se identifica o perfil socioeconômico dos domicílios de uma determinada população e suas condições de acesso ao insumo energético, criam-se condições de avaliação do nível de qualidade de vida daquela população.

\subsection{Procedimentos técnicos de investigação}

Os procedimentos técnicos desta investigação baseiam-se no suporte teórico do modelo PER, que envolve a relação pressão-estado-resposta desenvolvido pela Organização de Cooperação e Desenvolvimento Econômico (OCDE) em 1993. O suporte favorece sua utilização, pois possui uma visão de causalidade das pressões que as atividades humanas exercem sobre o ambiente, modificando a qualidade e a quantidade dos recursos naturais (Mendes, 2005). A construção de indicadores, entretanto, não pode ser realizada a partir de variáveis escolhidas de maneira desordenada. Questões precisam ser observadas, como disponibilidade de dados, coerência na associação de categorias a serem analisadas para a identificação do comportamento das relações, possibilidades identificadas de constatação prática e viabilidade de utilização das informações selecionadas para que os indicadores possam realmente ser úteis à tomada de decisão no setor elétrico.

Os indicadores e as variáveis são descritos a seguir: a) Indicadores: os indicadores no setor residencial fazem menção a áreas temáticas pertinentes ao desenvolvimento sustentável (os indicadores podem ser econômicos, sociais e ambientais); e b) Variáveis: as variáveis ou elementos de composição dos indicadores foram assim listados. O primeiro é o indicador econômico, caracterizado pelo consumo de eletricidade, tarifa de eletricidade, renda média e investimento em energia elétrica. O segundo é o indicador social, composto pela concentração de renda na camada mais pobre da população, investimento em eletricidade e consumo de eletricidade. Por fim, apresenta-se o indicador ambiental, formado pelo rendimento energético, emissão de gases e consumo de eletricidade.

No quadro 1 observa-se o esquema para a construção dos indicadores de sustentabilidade de energia elétrica. 


\section{Quadro 1
Esquema de construção de indicadores de sustentabilidade de energia elétrica no setor residencial}

\begin{tabular}{|c|c|}
\hline INDICADORES & VARIÁVEIS \\
\hline ECONÔMICO & $\begin{array}{l}\text { - Relação entre a quantidade de eletricidade consumida em GW no setor e o valor investido pela } \\
\text { distribuidora paraense em eletricidade no estado } \\
\text { - Relação entre a variação da tarifa média da eletricidade cobrada por kWh no setor residencial do } \\
\text { estado do Pará e o valor investido em eletricidade } \\
\text { - Relação entre a renda média do trabalhador paraense e a quantidade de GWh consumida no setor } \\
\text { residencial }\end{array}$ \\
\hline SOCIAL & $\begin{array}{l}\text { - Relação entre o percentual de renda dos 50\% mais pobres da população paraense e o valor investido } \\
\text { em eletricidade no Pará } \\
\text { Velação entre a quantidade consumida de eletricidade e o percentual de renda dos 50\% mais pobres } \\
\text { da população paraense }\end{array}$ \\
\hline AMBIENTAL & $\begin{array}{l}\text { - Relação entre a variação do rendimento energético verificado neste setor e a quantidade de GWh } \\
\text { consumida no setor } \\
\text { - Relação entre a variação da emissão acumulada de gás dióxido de carbono }\left(\mathrm{CO}_{2}\right) \text { derivado de } \\
\text { hidroelétricas no estado do Pará e a quantidade de } \mathrm{GWh} \text { consumida no setor residencial }\end{array}$ \\
\hline
\end{tabular}

Fonte: Autor (2011).

Apresentam-se, a seguir, os cálculos dos indicadores e das variáveis compostas. Os indicadores foram calculados a partir de uma média ponderada composta pelo resultado do cálculo das variáveis compostas. As variáveis compostas foram calculadas através da divisão entre duas variáveis. Uma referente ao processo de desenvolvimento, outra referente ao ambiente energético. Considerando que as variáveis compostas resultam da relação de variáveis de naturezas diferentes (unidades energéticas, valores em reais, toneladas e percentuais), adotou-se uma escala em quatro níveis para cada variável composta, como se pode observar no quadro 2.

\section{Quadro 2}

\section{Graduação de composição das variáveis dos indicadores}

\begin{tabular}{|c|c|c|c|}
\hline \multicolumn{4}{|c|}{ INDICADOR ECONÔMICO } \\
\hline Variável & Composição & Faixa & Nível \\
\hline \multirow[t]{4}{*}{$\begin{array}{l}\text { Quantidade de eletricidade em GW } \\
\text { consumida/valor investido em eletricidade }\end{array}$} & $\begin{array}{l}\text { Acima de } 25 \text { GW por milhão investido em eletri- } \\
\text { cidade }\end{array}$ & 4 & Alto \\
\hline & $\begin{array}{l}\text { Entre } 25 \text { e } 16 \text { GW por milhão investido em ele- } \\
\text { tricidade }\end{array}$ & 3 & Bom \\
\hline & $\begin{array}{l}\text { Entre } 15 \text { e } 6 \text { GW por milhão investido em eletri- } \\
\text { cidade }\end{array}$ & 2 & Médio \\
\hline & Até 5 GW por milhão investido em eletricidade & 1 & Baixo \\
\hline
\end{tabular}




\begin{tabular}{|c|c|c|c|}
\hline \multicolumn{4}{|c|}{ INDICADOR ECONÔMICO } \\
\hline Variável & Composição & Faixa & Nível \\
\hline \multirow{4}{*}{$\begin{array}{l}\text { Variação na tarifa de eletricidade/valor } \\
\text { investido em eletricidade }\end{array}$} & Acima de 0,20\% & 4 & Alto \\
\hline & Entre $0,20 \%$ e $0,16 \%$ & 3 & Bom \\
\hline & Entre $0,15 \%$ e $0,06 \%$ & 2 & Médio \\
\hline & Até 0,05\% & 1 & Baixo \\
\hline \multirow[t]{4}{*}{$\begin{array}{l}\text { Renda média/Quantidade de GW } \\
\text { consumida }\end{array}$} & $\begin{array}{l}\text { Acima de } R \$ 0,35 \text { de renda média por GW con- } \\
\text { sumido }\end{array}$ & 4 & Alto \\
\hline & $\begin{array}{l}\text { Entre } R \$ 0,35 \text { e } R \$ 0,31 \text { de renda média por GW } \\
\text { consumido }\end{array}$ & 3 & Bom \\
\hline & $\begin{array}{l}\text { Entre } R \$ 0,30 \text { e } R \$ 0,21 \text { de renda média por GW } \\
\text { consumido }\end{array}$ & 2 & Médio \\
\hline & Até $\mathrm{R} \$ 0,20$ de renda média por GW consumido & 1 & Baixo \\
\hline \multicolumn{4}{|c|}{ INDICADOR SOCIAL } \\
\hline Variável & Composição & Faixa & Nível \\
\hline \multirow{4}{*}{$\begin{array}{l}\text { Percentual de renda da população entre } \\
\text { os 50\% mais pobres/valor investido em } \\
\text { eletricidade }\end{array}$} & Acima de 0,25\% & 4 & Alto \\
\hline & Entre $0,25 \%$ e $0,21 \%$ & 3 & Bom \\
\hline & Entre $0,20 \%$ e $0,11 \%$ & 2 & Médio \\
\hline & Até $0,10 \%$ & 1 & Baixo \\
\hline \multirow{4}{*}{$\begin{array}{l}\text { Variação do consumo de GWh/Percentual } \\
\text { de renda da população entre os 50\% } \\
\text { mais pobres }\end{array}$} & Acima de 0,50\% & 4 & Alto \\
\hline & Entre $0,50 \%$ e $0,36 \%$ & 3 & Bom \\
\hline & Entre $0,35 \%$ e 0,21\% & 2 & Médio \\
\hline & Até 0,20\% & 1 & Baixo \\
\hline \multicolumn{4}{|c|}{ INDICADOR AMBIENTAL } \\
\hline Variável & Composição & Faixa & Nível \\
\hline \multirow{4}{*}{$\begin{array}{l}\text { Variação do rendimento energético no } \\
\text { setor/Quantidade de GWh consumida }\end{array}$} & Acima de 1,20\% & 4 & Alto \\
\hline & Entre $1,20 \%$ e $0,71 \%$ & 3 & Bom \\
\hline & Entre $0,70 \%$ e $0,21 \%$ & 2 & Médio \\
\hline & Até 0,20\% & 1 & Baixo \\
\hline \multirow{4}{*}{$\begin{array}{l}\text { Variação da emissão de gases poluentes } \\
\text { derivados de geração de eletricidade/ } \\
\text { Quantidade de GWh consumida }\end{array}$} & Acima de $0,85 \%$ & 4 & Alto \\
\hline & Entre $0,85 \%$ e $0,81 \%$ & 3 & Bom \\
\hline & Entre $0,80 \%$ e $0,71 \%$ & 2 & Médio \\
\hline & Até 0,70\% & 1 & Baixo \\
\hline
\end{tabular}

Fonte: Autor (2011).

Nota: A referência para determinação das faixas em cada variável composta obedeceu a uma dinâmica que respeitou uma observação histórica de todas as variáveis utilizadas durante um período entre 2001 e 2010 no estado do Pará. A opção por essa referência se deu por se considerar que é aquela que melhor mensura a relação entre o setor elétrico e o processo de desenvolvimento com base na realidade local, de modo a respeitar suas especificidades econômicas, tecnológicas, culturais e sociais. 


\subsection{Descrições das variáveis}

A descrição das variáveis torna-se fundamental na medida em que possibilita a compreensão da natureza de mensuração dos elementos que construirão os indicadores. Apresentam-se cada uma delas no quadro 3.

\section{Descrição das variáveis utilizadas no cálculo dos indicadores}

\begin{tabular}{|c|c|}
\hline VARIÁVEIS & DESCRIÇÃO \\
\hline Valor investido em eletricidade & $\begin{array}{l}\text { Registra a aplicação de recursos no setor elétrico paraense para expandir o sistema de eletrifi- } \\
\text { cação rural e urbano, além de reduzir as perdas de energia elétrica. A importância da análise do } \\
\text { investimento está pautada em sua relação com a capacidade produtiva. Assim, o investimento } \\
\text { significa a aplicação de capital em meios que levam ao crescimento dessa capacidade. A variável } \\
\text { é valorada nesta análise em milhões de dólares. }\end{array}$ \\
\hline $\begin{array}{l}\text { Quantidade consumida de } \\
\text { eletricidade }\end{array}$ & $\begin{array}{l}\text { Altas taxas de mortalidade infantil, analfabetismo e baixa qualidade de vida geralmente são } \\
\text { indiretamente ligados a um baixo consumo de energia elétrica per capita. Por outro lado, a } \\
\text { expansão do consumo de energia per capita não equivale necessariamente a uma melhoria na } \\
\text { qualidade de vida da população, já que existem populações que apresentam diferentes níveis } \\
\text { de consumo de eletricidade e semelhantes níveis de qualidade de vida. A variável consumo } \\
\text { de energia elétrica é medida em GWh por ano. }\end{array}$ \\
\hline Tarifa média de eletricidade & $\begin{array}{l}\text { Compreendem tarifas pagas pela prestação de serviços públicos de energia elétrica. As tarifas } \\
\text { são cobradas através da unidade de medida KWh. Quando analisadas através dos setores de } \\
\text { atividade econômica, indicam diferentes preços que podem ser confrontados com o retorno } \\
\text { socioeconômico de cada setor para a sociedade. A variável é mensurada em } \mathrm{R} \$ / \mathrm{KWh} \text {. }\end{array}$ \\
\hline Renda média do trabalhador & $\begin{array}{l}\text { Equivale ao que o trabalhador paraense recebe a título de rendimento mensal. Em face do } \\
\text { extremo cenário nacional de desigualdade na distribuição de renda, essa variável procura } \\
\text { identificar a capacidade de satisfação das necessidades básicas por parte dos trabalhadores } \\
\text { no estado do Pará. A variável é quantificada anualmente em reais. }{ }^{1}\end{array}$ \\
\hline Rendimento energético & $\begin{array}{l}\text { É o produto da relação entre a quantidade de energia final, que é consumida segundo diferentes } \\
\text { usos finais, e a energia útil efetivamente consumida para a produção de bens e/ou serviços. } \\
\text { A variável é quantificada em valores percentuais e baseia-se em informações do Balanço de } \\
\text { Energia Útil (BEU). }\end{array}$ \\
\hline $\begin{array}{l}\text { Quantidade de emissões de } \\
\text { gases poluentes }\end{array}$ & $\begin{array}{l}\text { Os gases poluentes oriundos da geração de eletricidade no Pará são caracterizados, predomi- } \\
\text { nantemente, pelo dióxido de carbono }\left(\mathrm{CO}_{2}\right) \text {. Esse componente detém relevância de análise } \\
\text { pelas proporções de quantidade emitidas e pelos impactos causados na atmosfera. A geração } \\
\text { de energia elétrica também contribui neste contexto, pois o fechamento de um rio por uma } \\
\text { barragem provoca uma alteração estrutural em que as águas passam de um sistema corrente } \\
\text { para um sistema de água parada, com taxas de emissões diferentes. O componente observado } \\
\text { é estimado em toneladas. }\end{array}$ \\
\hline $\begin{array}{l}\text { Parcela de renda entre os } \\
50 \% \text { mais pobres }\end{array}$ & $\begin{array}{l}\text { Compreende uma variável de identificação da disposição global da renda em uma determinada } \\
\text { região. Quanto maior o percentual da renda de uma determinada população estiver alocado } \\
\text { entre os 50\% mais pobres, menor será sua concentração de renda. A variável é quantificada } \\
\text { em bases percentuais. }\end{array}$ \\
\hline
\end{tabular}

Fonte: Autor (2011).

1 Os valores referentes à renda média do paraense durante o período analisado neste estudo foram corrigidos monetariamente pela própria fonte fornecedora, o IBGE (2009). 


\section{Análise e interpretação de resultados}

Na análise e interpretação de dados, apresentam-se os resultados e as análises dos indicadores de sustentabilidade energética no setor residencial paraense entre os anos 2001 e 2010. Observem os quadros 4 e 5 .

Quadro 4

Resultado das variáveis de sustentabilidade de energia elétrica no setor residencial do Pará entre 2001 e 2010

\begin{tabular}{|c|c|c|c|c|c|c|c|c|c|c|c|}
\hline INDICADORES & VARIÁVEIS & 2001 & 2002 & 2003 & 2004 & 2005 & 2006 & 2007 & 2008 & 2009 & 2010 \\
\hline \multirow{3}{*}{ ECONÔMICO } & $\begin{array}{l}\text { Quantidade de eletricidade em } \\
\text { GW consumida/Valor investido } \\
\text { em eletricidade }\end{array}$ & 3 & 3 & 3 & 2 & 2 & 1 & 1 & 1 & 1 & 1 \\
\hline & $\begin{array}{l}\text { Variação na tarifa de eletricidade/ } \\
\text { Valor investido em eletricidade }\end{array}$ & 2 & 3 & 3 & 2 & 2 & 1 & 1 & 1 & 1 & 1 \\
\hline & $\begin{array}{l}\text { Renda média/Quantidade de GW } \\
\text { consumida }\end{array}$ & 2 & 2 & 1 & 1 & 3 & 4 & 4 & 3 & 4 & - \\
\hline \multirow{2}{*}{ SOCIAL } & $\begin{array}{l}\text { Percentual de renda da popula- } \\
\text { ção entre os 50\% mais pobres/ } \\
\text { Valor investido em eletricidade }\end{array}$ & 3 & 3 & 3 & 2 & 1 & 1 & 1 & 1 & 1 & - \\
\hline & $\begin{array}{l}\text { Variação do consumo de GWh/ } \\
\text { Percentual de renda da popula- } \\
\text { ção entre os 50\% mais pobres }\end{array}$ & 4 & 1 & 3 & 2 & 3 & 1 & 3 & 2 & 3 & - \\
\hline \multirow[b]{2}{*}{ AMBIENTAL } & $\begin{array}{l}\text { Variação do rendimento energé- } \\
\text { tico no setor/Quantidade de GW } \\
\text { consumida }\end{array}$ & 1 & 4 & 2 & 3 & 2 & 4 & 2 & 2 & 2 & 2 \\
\hline & $\begin{array}{l}\text { Variação da emissão de gases } \\
\text { poluentes derivados de geração } \\
\text { de eletricidade/Quantidade de } \\
\text { GW consumida }\end{array}$ & 4 & 4 & 3 & 2 & 2 & 2 & 1 & 1 & 1 & 1 \\
\hline
\end{tabular}

Fonte: Autor (2011).

Quadro 5

Resultado dos indicadores de sustentabilidade de energia elétrica no setor residencial do Pará entre 2001 e 2010

\begin{tabular}{|c|ccccccccccc|}
\hline INDICADOR & 2001 & 2002 & 2003 & 2004 & 2005 & 2006 & 2007 & 2008 & 2009 & 2010 \\
\hline Econômico & Médio & Bom & Médio & Médio & Médio & Médio & Médio & Médio & Médio & - \\
Social & Bom & Médio & Bom & Médio & Médio & Baixo & Médio & Médio & Médio & - \\
Ambiental & Médio & Alto & Médio & Médio & Médio & Bom & Baixo & Baixo & Baixo & Baixo \\
\hline
\end{tabular}

Fonte: Autor (2011). 
A seguir, apresenta-se a análise dos indicadores econômico, social e ambiental:

\section{a) Indicador econômico}

O indicador econômico do setor residencial é composto pelas relações: quantidade de eletricidade em GW consumida no setor residencial $\times$ valor investido em eletricidade no Pará; variação na tarifa de eletricidade cobrada no setor $\times$ valor investido em eletricidade no estado; e renda média do paraense $\times$ quantidade de GW consumida no setor.

Quanto à variável composta que analisa a relação entre a quantidade de eletricidade em GW consumida no setor e o valor investido em eletricidade, verificou-se que os valores foram decrescendo. O contexto justifica-se em virtude de os investimentos em energia elétrica terem crescido em percentuais mais elevados do que o aumento do consumo de energia elétrica no setor. O programa de universalização da eletricidade avançou bastante durante o período estudado, porém os grandes centros de consumo de eletricidade já haviam sido atendidos em sua quase totalidade.

Registrou-se uma tendência decrescente ao se observar a relação entre a variação na tarifa de eletricidade no setor residencial e o valor investido em eletricidade no estado. O resultado é explicado pelo aumento percentual do investimento em eletricidade no estado, que se deu em maior proporção que o aumento percentual da tarifa cobrada pela eletricidade no setor residencial.

A relação entre a renda média do paraense e a quantidade de GW consumida no setor residencial apresentou valores com tendência global crescente. O cenário justifica-se pelo aumento da renda média do paraense, que se apresentou em maiores proporções percentuais que o aumento da quantidade de eletricidade consumida nos domić́lios.

Todo este contexto pontuou o indicador econômico do setor residencial durante o período analisado como de desempenho dominantemente "Médio", com registros de "Bons" desempenhos para os anos de 2001 e 2002.

\section{b) Indicador social}

O indicador social do setor residencial é formado pelas seguintes variáveis compostas: percentual de renda da população paraense entre os $50 \%$ mais pobres $\times$ valor investido em eletricidade no Estado; e variação do consumo de Gwh no setor residencial $\times$ percentual de renda da população paraense entre os $50 \%$ mais pobres.

Foi constatada uma tendência decrescente no tocante à relação entre o percentual de renda da população entre os $50 \%$ mais pobres e o valor investido em eletricidade. Esse quadro se deu em virtude de o crescimento do investimento em eletricidade ter sido verificado em proporções superiores que as do aumento percentual da renda da população paraense 
entre os 50\% mais pobres. Isso não equivale a dizer que os investimentos em eletricidade no Pará não estejam contribuindo para a desconcentração de renda no estado, apenas ocorreram investimentos significativos e necessários ao avanço dos programas de universalização da eletricidade no estado, enquanto a desconcentração de renda não representa resultado apenas do processo de eletrificação.

Quanto à variável composta que apura a variação do consumo de Gwh no setor residencial e o percentual de renda da população entre os 50\% mais pobres, observaram-se várias oscilações durante o período estudado. Ambas as variáveis apresentaram no período analisado comportamentos inconstantes que redundaram em resultados oscilantes quando do cruzamento destas. O ano de 2001, que pontuou alto consumo de energia elétrica no setor residencial no período observado, foi seguido de um aumento do percentual de renda da população paraense entre os 50\% mais pobres, o que revela um indicativo de desconcentração de renda.

Este quadro pontuou, para o indicador social do setor residencial, desempenhos "Médio", "Bom" e "Alto". O registro negativo ficou a cargo do ano de 2006, com "Baixo" desempenho registrado.

\section{c) Indicador ambiental}

O indicador ambiental do setor residencial é formado pelas variáveis compostas: variação do rendimento energético no setor residencial $\times$ quantidade de GW consumida no setor; variação da emissão de gases poluentes derivados de geração de eletricidade no Pará $\times$ quantidade de GW consumida no setor residencial.

No que se refere à variação do rendimento energético no setor residencial e a quantidade de GW consumida no setor, destaca-se um comportamento oscilante, haja vista que ambas as variáveis apresentam-se inconstantes no comportamento. Entretanto, chama-se a atenção que a variação da quantidade de GW consumida é mais determinante neste cenário na medida em que o rendimento energético apresenta historicamente alterações discretas por referir-se a melhorias técnicas de luminárias e equipamentos que possam utilizar o insumo elétrico com maior eficiência.

Quanto à relação entre variação da emissão de gases poluentes derivados de geração de eletricidade e a quantidade de GW consumida no setor, registrou-se uma tendência de decréscimo em virtude do contraste entre a estabilidade das emissões de gases e o aumento constante da quantidade consumida de eletricidade no setor.

Diante deste quadro, o indicador ambiental do setor residencial apresentou desempenhos dominantemente "Médios", porém registrando "Baixos" desempenhos nos dois últimos anos na medida em que os níveis de satisfação do paraense quanto aos serviços de eletricidade oferecidos pela distribuidora diminuíram bastante. 


\section{Conclusão}

O universo de investigação de caminhos para a construção de uma proposta de indicadores capaz de mensurar a sustentabilidade dos resultados dos investimentos em energia elétrica dentro das residências dos paraenses refletiu uma dinâmica complexa e desafiadora.

O estado do Pará apresentou uma modificação em suas características econômicas que compreende o resultado de uma política energética que tem fornecido relativo suporte à modernização do perfil tecnológico nos arranjos produtivos e na dinamização de cadeias produtivas locais. O processo de modernização da administração pública e o fortalecimento global de investimentos infraestruturais contribuíram para esses avanços. Entretanto, acredita-se que a tendência de crescimento dos investimentos em energia elétrica e o aumento constante do consumo desse insumo em todos os setores de atividade no Pará poderiam ser vinculados estrategicamente ao processo de melhoria concreta das condições de vida dos paraenses de forma sustentável.

Desde pesquisas de Silva (2005), vários aspectos colaboram para que o padrão de vida do paraense não acompanhe a velocidade do crescimento dos investimentos: a expansão demográfica acelerada, a maximização do lucro na oferta de eletricidade, os elevados custos e tarifas de eletricidade e a lentidão na eletrificação rural. Borges (2007) acrescenta que a energia elétrica é gerada no estado do Pará em função de elites e do interesse nacional representado por regiões mais desenvolvidas economicamente. A melhoria do perfil socioeconômico do estado, verificado nos últimos 10 anos, representa apenas uma pequena fatia das possibilidades que poderiam ter sido desenhadas junto à realidade local, enquanto os impactos ambientais representam o legado de uma energia elétrica gerada localmente e que não se utiliza, em maior parte, no estado. Esta dinâmica, através de um processo dialético, faz com que o favorecimento dessas elites, na figura de grandes grupos econômicos, implique, necessária e contraditoriamente, o fortalecimento dos vários grupos atingidos pelos impactos dessa geração através de um amplo processo de exclusão social.

A análise da relação entre energia elétrica e desenvolvimento sustentável no Pará constitui-se em um campo complexo de estudo. Essa complexidade aumenta ainda mais quando se sabe que a energia elétrica não é a única responsável por um processo de desenvolvimento socioeconômico. Entretanto, apenas através da construção de indicadores que possam mensurar a sustentabilidade dos resultados dos investimentos em energia elétrica dentro das residências dos paraenses é que se levantam condições mais estratégicas para o processo de tomada de decisão no setor elétrico paraense.

O setor residencial é composto pelos consumidores domiciliares conectados regularmente às redes de distribuição de energia elétrica. A demanda mensal padrão por domicílio brasileiro a ser considerada como base de cálculo no país é de $220 \mathrm{kWh} / \mathrm{mês}$. Com base nessa média e considerando o número de unidades consumidoras de energia elétrica do estado em 2005, o Pará deveria ter anotado, aproximadamente, um consumo anual no setor de 3.060 GW. Entretanto, 
o consumo de energia elétrica do setor residencial foi de $1.055 \mathrm{GW}$, o que correspondeu a uma média mensal de 75,83 kWh por mês, isto é, abaixo da média brasileira.

Os resultados dos indicadores de sustentabilidade de energia elétrica no setor residencial paraense durante o período 2001-10 revelaram desempenhos dominantemente "médios". Mais precisamente os resultados demonstram que o aspecto econômico é o que melhor reflete o insumo elétrico nos domicílios paraenses. O aumento gradativo da renda média, reflexo da disponibilidade de eletricidade e do aumento do consumo, teve papel importante neste resultado, que registrou ainda, em 2001 e 2002, bons desempenhos. O aspecto socioambiental apresentou indicadores médios com sensível tendência decrescente. Esse quadro revela um alerta ao estado paraense na medida em que o aspecto social tem o papel de contribuir para a desconcentração de renda e o aspecto ambiental revela os impactos da utilização do insumo elétrico no ecossistema.

O Pará é detentor de grandes potencialidades naturais e de notado potencial exportador de eletricidade, porém os desafios não estão apenas associados à garantia da disponibilidade desse insumo. A redução das desigualdades e da pobreza, a universalização do acesso à energia elétrica e a minimização dos custos e dos danos ambientais oriundos de sua geração em muito caracterizam a realidade paraense. Seu grande potencial hidroelétrico a partir de grandes projetos é classificado como energia "limpa", que cada vez mais procura atender a crescente demanda por eletricidade. Contudo, a construção destes projetos implica bruscos impactos no ciclo hidrológico e mudanças no meio ambiente de modo geral.

Diante deste panorama, destaca-se que o estado do Pará precisa estar preparado para o enfrentamento da insegurança na oferta de eletricidade e para o desafio da problemática ambiental. O setor elétrico paraense não pode prescindir de desenvolver um processo de diversificação na disposição das fontes de eletricidade na medida em que esta ação representa uma resposta aos novos padrões de competitividade e aos graves problemas ambientais decorrentes da geração e uso de energia elétrica. A partir do enfrentamento dos desafios de um processo de diversificação das fontes de eletricidade a população paraense poderá promover uma melhoria concreta e sustentável de seu padrão de vida e transformar todo seu potencial energético em altos indicadores de desempenho econômico, social e ambiental dentro das residências dos paraenses.

Todavia, os resultados alcançados nesta presente investigação já podem orientar a tomada de decisão no setor elétrico paraense na medida em que os indicadores esclarecem como a energia elétrica interage no setor residencial a partir de aspectos econômicos, sociais e ambientais, isto é, as ações públicas poderiam ser construídas na intenção de criar mecanismos que favoreçam as potencialidades do insumo energético no referido setor. Assim, as práticas de desenvolvimento poderiam ser planejadas estrategicamente a partir de ações públicas balizadas pelos indicadores de sustentabilidade energética, capazes inclusive de demonstrar como os investimentos em eletricidade darão resultado no ambiente residencial dos paraenses. 


\section{Referências}

BORGES, Fabricio Quadros. Setor elétrico e desenvolvimento no estado do Pará: uma análise estratégica de indicadores de sustentabilidade. Tese (doutorado em desenvolvimento socioambiental) — Núcleo de Altos Estudos Amazônicos, Universidade Federal do Pará, Belém, 2007.

CADASTRO GERAL DE EMPREGADOS E DESEMPREGADOS. Estatísticas das bases de dados do MTE. Disponível em: <www.caged.gov.br/index.html>. Acesso em: 21 nov. 2005.

CAMARGO, A.S.G. et al. Proposta de definição de indicadores de sustentabilidade para geração de energia elétrica. Revista Educação e Tecnologia, Rio de Janeiro, n. 8, p. 51-60, set. 2004.

CENTRAIS ELÉTRICAS BRASILEIRAS. Relatório sobre geração, fornecimento e suprimento de energia elétrica na Região Norte/Nordeste. Brasília, 2004.

CENTRAIS ELÉTRICAS DO NORTE DO BRASIL. Relatório de acompanhamento do mercado de energia elétrica. Brasília, 1999.

CENTRAIS ELÉTRICAS DO NORTE DO BRASIL. Amazônia: cenários socioeconômicos e de demanda de energia elétrica. Brasília, 2005.

CENTRAIS ELÉTRICAS DO NORTE DO BRASIL. Portal disponível em: <www.eln.gov.br/>. Acesso em: 25 jan. 2007.

CENTRAIS ELÉTRICAS DO PARÁ. Relatório da administração: exercício de 2005. Belém, 2006.

CENTRAIS ELÉTRICAS DO PARÁ. Relatório da administração: exercício de 2004. Belém, 2005.

CENTRAIS ELÉTRICAS DO PARÁ. Relatório da administração: exercício de 2003. Belém, 2004.

CENTRAIS ELÉTRICAS DO PARÁ. Relatório da administração: exercício de 2001. Belém, 2002.

CENTRAIS ELÉTRICAS DO PARÁ. Relatório da administração: exercício de 2000. Belém, 2001.

GOMES, J.P.P.; VIEIRA, M.M.F. O campo da energia elétrica no Brasil de 1880 a 2002. Revista de Administração Pública, v. 43, n. 2, p. 295-321, 2009.

INSTITUTO BRASILEIRO DE GEOGRAFIA E ESTATÍSTICA. Rio de Janeiro, 2009. Download: população banco de dados. Disponível em: <www.ibge.gov.br/home/redir_download.php>. Acesso em: 20 jan. 2009.

KALTENEGGER, C.H. Der Reformproze in der VR China: aktueller stand der wirtschaftsreformen und aussichten. [s.l.]: [s.n.], 1995.

KITAMURA, P.C. A Amazônia e o desenvolvimento sustentável. Brasília: Embrapa, 1994.

MACHADO, N.; HOLANDA, V.B. de. Diretrizes e modelo conceitual de custos para o setor público a partir da experiência no governo federal do Brasil. Revista de Administração Pública, Rio de Janeiro, v. 44, n. 4, p. 791-820, jul./ago. 2010.

MENDES, R.L.R. Indicadores de sustentabilidade do uso doméstico de água. Tese (doutorado em desenvolvimento sustentável do trópico úmido) — Núcleo de Altos Estudos Amazônicos, Universidade Federal do Pará, Belém, 2005. 
REDCLIFT, M. Sustainable development: exploring the contradictions. London: Routledge, 1987.

REIS, L.B. et al. Energia, recursos naturais e a prática do desenvolvimento sustentável. Barueri: Manole, 2005. (Ambiental)

SECRETARIA EXECUTIVA DE ESTADO DE PLANEJAMENTO, ORÇAMENTO E FINANÇAS. Secretaria de planejamento, orçamento e finanças. Disponível em: <www.sepof.pa.gov.br/seplan/Para_em_numeros/PDFs/DESENVOLVIMENTO_DA_INFRAESTRUTURA/EnergiaEletrica/Consumo_de_Energia_Eletrica.pdf $>$. Acesso em: 17 set. 2009.

SILVA, M.V.M. da. A dinâmica excludente do sistema elétrico paraense. Tese (doutorado em interunidades em energia) — EP/FEA/IEE/IF, Universidade de São Paulo, São Paulo, 2005.

SMIL, V. China's environmental crisis: an inquiry into the limits of national development. New York: East Gate, 1993.

SPANGENBERG, J.H. Measuring and communicating sustainability with indicators: terms of reference for a CSD core indicator test in main catchment area regions. New York: UN/E/CN, 2000.

Fabricio Quadros Borges é professor titular do Programa de Mestrado em Administração da Universidade da Amazônia (Unama). E-mail: doctorborges@bol.com.br. 
